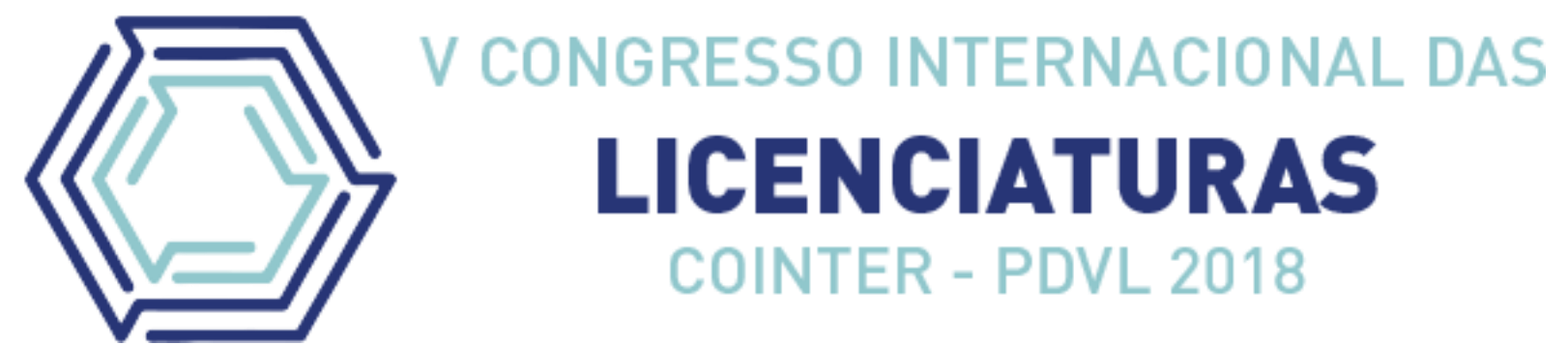

\title{
PERSPECTIVAS DOS ALUNOS INGRESSANTES NO PIBID E RESIDÊNCIA PEDAGÓGICA NOS CURSOS DE LICENCIATURA EM QUÍMICA E MATEMÁTICA NO IFPI - CAMPUS TERESINA CENTRAL
}

\section{PERSPECTIVES OF STUDENTS IN THE PIBID AND PEDAGOGICAL RESIDENCE IN THE COURSES OF LICENSE IN CHEMISTRY AND MATHEMATICS IN IFPI - CAMPUS TERESINA CENTRAL}

\author{
Apresentação: Pôster \\ Maria Lanna Souza da Silva ${ }^{1}$; Cleiton Pedrosa de Sales²; Rafael Lisandro P. Rocha ${ }^{3}$ \\ DOI: https://doi.org/10.31692/2358-9728.VCOINTERPDVL.2018.00236
}

\section{Introdução}

Os alunos de licenciatura no decorrer da vida acadêmica encontram diversos desafios, sendo um deles, unir a teoria e a prática. Os programas PIBID e Residência Pedagógica a partir da união entre educação básica e superior vieram para sanar essas dificuldades, envolvendo os discentes nesses programas aprimorando o saber e a prática na formação docente, sendo este um elemento influenciador a respeito a sua carreira profissional.

O Pibid e Residência Pedagógica tem como principais metas estimular e imergir o licenciando de licenciatura a adentrar, conhecer e vivenciar diversas realidades da escola campo, e as possibilidades e alternativas para exercer a docência.

Neste resumo vamos relatar sobre as perspectivas dos alunos ingressantes nos programas Pibid e Residência Pedagógica nos cursos de licenciatura nas disciplinas de Química e Matemática do Instituto Federal do Piauí - Campus Teresina Central, tendo esses programas uma oportunidade de vivências e experiências de forma concreta na formação acadêmica durante a graduação.

\section{Fundamentação Teórica}

\footnotetext{
${ }^{1}$ Licenciatura em Química, IFPI, lannalanninha2008@hotmail.com

${ }^{2}$ Licenciatura em Matemática, IFPI, csales.ifpi.edu@gmail.com

${ }^{3}$ Mestre, IFPI, rafael@ifpi.edu.br
} 
Sempre no dia a dia estamos em constante relação com o próximo. No âmbito escolar, os alunos têm sempre a imagem do professor como referência. Quanto às diversas experiências vividas no espaço escolar (NÓVOA, 2003) vai dizer que "é evidente que a instituição de ensino tem um papel importante a desempenhar na formação de professores. A bagagem essencial de um professor adquire-se na escola, através de experiências e da reflexão sobre a experiência. Esta reflexão não surge do nada, tem regras e métodos próprios.

Em relação a melhorias na formação de professores, o Governo Federal exerce um papel de articular nas políticas públicas em relação a criação aos programas de formação dos professores durante a formação a nível de graduação.

É neste contexto que houve então o surgimento do Pibid e o mais recente programa Residência pedagógica. O pibid, sendo uma proposta de valorização da formação inicial de futuros docentes, apresenta os seguintes objetivos de acordo com (BRASIL, 2010) "reconhecer a relevância social da carreira docente; promover a articulação teoria-prática e integração entre escolas e instituições formadoras; contribuir para elevar a qualidade dos cursos de formação de educadores e o desempenho das escolas nas avaliações, e no seu IDEB”.

\section{Metodologia}

Este trabalho foi aplicado no Instituto Federal de Educação, Ciência e Tecnologia do Piauí com uma natureza quantitativa, buscando analisar as perspectivas dos alunos dos cursos de Licenciatura em Química e Matemática ingressantes nos programas de iniciação à docência (PIBID) e Residência Pedagógica (RP). O Mesmo foi realizado no formato de questionário, onde foi questionado sobre experiências anteriores e novas perspectivas dos alunos ingressantes.

\section{Resultados e Discussões}

Como mencionado foram utilizados questionário, fazendo uma abordagem quantitativa realizando a análise quanto a perspectiva dos alunos ao programa PIBID e RP (residência pedagógica), quantificando assim as respostas das perguntas objetivas do questionário.

Dos 43 alunos que responderam a pesquisa, foram considerados para a análise de resultados 25 alunos do curso de Química e 18 alunos do curso de Matemática do IFPI - Campus Teresina Central. As respostas das questões objetivas deste trabalho foram analisadas separadamente por curso (matemática e química) e por programa (pibid e rp). 
Em relação a RP foram levados em consideração os alunos que tiveram experiências no PIBID tendo dois pontos, o positivo e o negativo por meio da seguinte análise: I) Irei me adequar rapidamente pois já tive experiências que me proporcionaram um crescimento significativo; II) Acredito que terei dificuldade, pois não aproveite as ferramentas necessárias no decorrer do programa. O gráfico 1 apresenta os dados correspondentes a estes dois pontos abordados.

Gráfico 1: Respostas dos alunos quanto aos pontos positivos e negativos sobre a Residência Pedagógica.
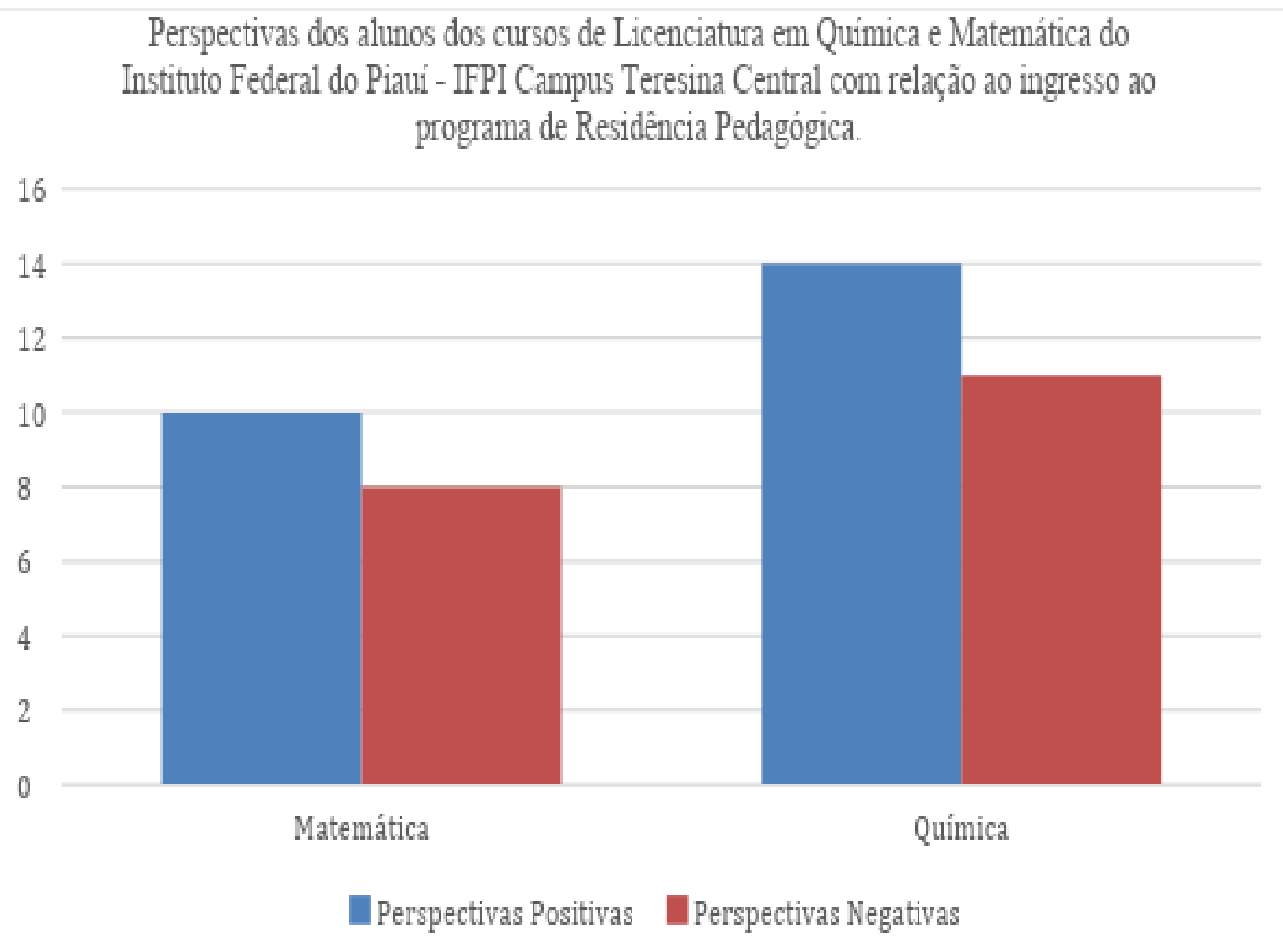

Pode-se então perceber que os alunos residentes que atuaram no Pibid em ambos os cursos na sua maioria relataram que irá se adequar a este programa já que tiveram experiências na qual possibilita uma vivência do dia a dia no ambiente escolar. Já a outra parte dos alunos relataram que terão dificuldades pois não tiveram a oportunidade de ter participado do Pibid.

Quanto ao programa Pibid os pontos positivos e negativos foram feitos por meio da seguinte análise: I) Será uma experiência positiva pois teremos um contato com a escola mais cedo; II) Não acredito que causará um impacto significativo na minha formação profissional. O gráfico 2 apresenta os dados correspondentes a esta análise a estes dois pontos abordados.

Gráfico 2: Respostas dos alunos quanto aos pontos positivos e negativos sobre o Pibid.. 


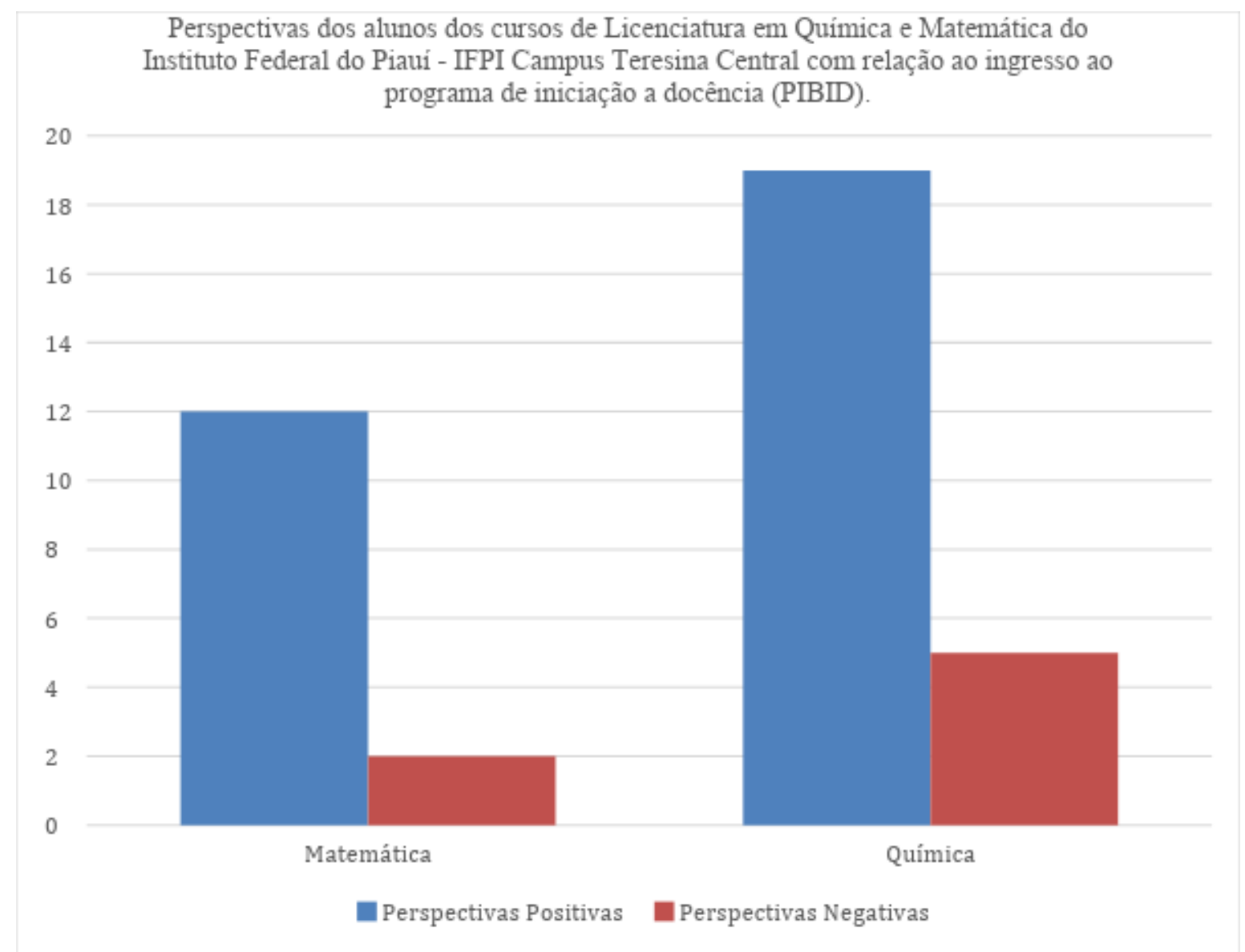

Já em relação a análise feita com os alunos que ingressaram no Pibid, a grande maioria em ambos os cursos relataram que será uma experiência positiva pois teremos um contato mais cedo com a escola. A minoria relatou que não acreditam que causará um impacto significativa na formação profissional.

Em relação aos impactos do Pibid nas práticas formativas dos cursos de Licenciatura (Canário, 2001) vai dizer que "ao mostrar novas alternativas e experiências sucedidas de formação, os programas indicam possibilidades de avanço no sentido de uma maior articulação entre o contexto de formação, bem como o trabalho docente, beneficiando todos os envolvidos no processo".

\section{Conclusões}

Os programas Pibid e Residência Pedagógica atuam favorecendo a união do graduando com a escola de educação básica juntamente com a instituição de ensino, por meio de execução e preparação de atividades para esse público. Ao realizar as análises, pode-se perceber a importância atribuída a esses programas durante a formação inicial embasada assim por experiências no âmbito escolar visando ações, intervenções acerca dos mesmos. É fácil então 
perceber a contribuição, à imersão destes programas para a melhoria da formação inicial dos professores.

\section{Referências}

BRASIL. Portaria normativa ${ }^{\circ}$ 260, de 30 de dezembro de 2010. Normas gerais do Programa Institucional de Bolsa de Iniciação à Docência - PIBID. Disponível em: <http://capes.gov.br/images/stories/download/legislacao/Portaria260_PIBID2011_NomasGer ais.pdf>. Acesso em: 30 set. 2018.

CANÁRIO, Rui. A prática profissional na formação de professores. In: CAMPOS, Bártolo Paiva. Formação profissional de professores no ensino superior. Porto: Porto Editora, 2001.

NÓVOA, A. (Org.). Cúmplices ou reféns? Nova Escola. São Paulo: Abril; n. 162, p. 14-15, mai. 2003. 